\title{
An investigation of the equiratio-mixture model in olfactory psychophysics: A case study
}

\author{
FRANC T. SCHIET and JAN E. R. FRIJTERS \\ Agricultural University, Wageningen, The Netherlands
}

\begin{abstract}
The psychophysical function of one olfactory equiratio-mixture type was examined in relation to the functions of its constituents, $\alpha$-terpineol and 1-decanol. Suppression occurred over the entire concentration range used; that is, values predicted for the mixture by the equiratio mixture model were higher than those determined experimentally. The model consistently underestimated the intensities of the mixtures. The difference between the predicted and the experimentally obtained functions was probably caused by suppression at a central level.
\end{abstract}

Several studies of odor interaction in odorant mixtures have shown that odor compensation and odor compromise occur for suprathreshold odorant concentrations (e.g., Berglund, 1974; Cain, 1975; Jones \& Woskow, 1964; Laing, Panhuber, Willcox, \& Pittman, 1984; Moskowitz \& Barbe, 1977). In general, the odor intensity of a mixture is found to be less than the sum of the intensities of its components when these components are judged separately at the corresponding concentrations present in the mixture (Cain \& Drexler, 1974). Various psychological and psychophysical models have been devised to predict the odor intensity of such mixtures (Frijters, 1987; Laffort \& Dravnieks, 1982). In general, in these models, the proportion of one odorant relative to another varies within a mixture series. A good illustration of such a mixtureseries type was given by Gregson (1986, Figure 2). The concentration of one odorant was increased from $0 \%$ to $100 \%$, and the concentration of the other odorant decreased inversely. Thus, the dominant odor type of such a mixture series is supposed to shift from one component to the other. Laing and Willcox (1983) showed that, if the components in a binary mixture have approximately equal intensity when smelled individually, neither of the component's odor quality dominates. In the present study, such mixtures will be described as eliciting homogeneous percepts.

The equiratio-mixture model was specifically designed to predict the intensities of such mixtures. First applied in gustatory psychophysics, it was shown to have high validity for binary mixtures of tastants (Frijters, De Graaf, \& Koolen, 1984; Frijters \& Oude Ophuis, 1983; Frijters \& Stevens, 1986) as well as for multicomponent mixtures (Frijters \& De Graaf, 1987). The first condition for application of this model is that there be cross-adaptation between the substances to be used for mixture composi-

The authors would like to thank J. M. H. Bemelmans for useful suggestions concerning the headspace gas chromatographic analysis, and International Flavors and Fragrances Nederland (B.V.) for supplying the materials used in the experiment. Address correspondence to Jan E. R. Frijters, Department of Food Science, Agricultural University, De Dreijen 12, 6703 BC Wageningen, The Netherlands. tion; Frijters and Oude Ophuis (1983) called such substances "sensory dependent." The second condition is that a particular ratio between the concentrations of constituents must give rise to a homogeneous mixture percept. This condition can easily be met in gustation, where qualities are classified into four primary categories. Mixin two stimuli with the same taste quality will result in a mixture with that quality (e.g., sweet + sweet $\rightarrow$ sweet). Olfaction, on the other hand, does not have a definite se of categories (Cain, 1987).

In this study, we attempted to explore the equiratiomixture model in olfactory psychophysics. The substance. used for mixture composition were 1-decanol an $\alpha$-terpineol. Although these substances have different odor qualities, they were chosen to enable us to investigate whether the equiratio-mixture model had some potentia in olfactory psychophysics. In a preliminary experiment. mixtures of these substances that generated homogene ous percepts were obtained.

\section{THE EQUIRATIO MODEL}

In general, an equiratio mixture is a series of mixture. in each of which the ratio of concentrations of the com. ponents $A$ and $B$ is constant. A particular mixture of such a series is constructed by adding the concentrations $C_{\mathrm{a}}$ and $C_{\mathrm{b} j}$; the resulting concentration is denoted as $C_{\mathrm{ab} i j p q}$ Indices $i$ and $j$ refer to a particular concentration of $A$ anc $B$, respectively, and $p$ and $q$ are proportions of the com ponents in the mixture such that

$$
\frac{C_{\mathrm{a} i} / C_{\mathrm{abijpq}}}{C_{\mathrm{b} j} / C_{\mathrm{abijpq}}}=\frac{p}{q},
$$

and

$$
p+q=1 .
$$

Thus, a proportion $p$ of the binary mixture type $C_{\mathrm{ab} i j p}$ consists of component $A$ at concentration $i$, with the re maining proportion $q$ at concentration $j$ of component The ratio $C_{a}$ and $C_{b j}$ is constant throughout the entir range of $C_{\mathrm{ab} i j p q}{ }^{1}$ 
The psychophysical function of an equiratio-mixture type is similar to those of its components,

$$
R_{\mathrm{a}}=k_{\mathrm{a}} C_{\mathrm{a}}^{\mathrm{m}}
$$

and

$$
R_{\mathrm{b}}=k_{\mathrm{b}} C_{\mathrm{b}}^{\mathrm{n}}
$$

The predicted sensory response, $\hat{R}_{\mathrm{ab} i j p q}$, to the mixture concentration, $C_{\mathrm{abijpq}}$, is described as

$$
\hat{R}_{\mathrm{a} \delta_{i j p q}}=k_{\mathrm{ab} i j p q} C_{\mathrm{ab} i j p q}^{\mathrm{mpt} q}
$$

The exponent of the psychophysical function of this particular equiratio-mixture type is obtained from the exponents of substances $A$ and $B$ (Equations $3 \mathrm{a}$ and $3 \mathrm{~b}$ ), and is calculated using their equiratio proportions, $p$ and $q$, as weights in the determination of the arithmetic mean. In the model, the constant $k_{\mathrm{ab} i j p q}$ is estimated on the basis of the constants $k_{\mathrm{a}}$ and $k_{\mathrm{b}}$ in Equations $3 \mathrm{a}$ and $3 \mathrm{~b}$, and the proportions $p$ and $q$ of the components in the equiratio mixture. The concentrations, $C_{\mathrm{as}}$ and $C_{\mathrm{bs}}$, of the components $A$ and $B$, respectively, are defined as the stimulus concentrations that give rise to the same response of the standard stimulus in a matching task. The standard stimulus concentration was also one of the stimuli presented in the present experiment (for details, see Frijters \& Oude Ophuis, 1983).

$$
k_{\mathrm{abijpq}}=\frac{\left(p k_{\mathrm{a}} / C_{\mathrm{as}}\right)+\left(q k_{\mathrm{b}} / C_{\mathrm{bs}}\right)}{\left(p / C_{\mathrm{as}}\right)+q\left(C_{\mathrm{bs}}\right)}
$$

\section{EXPERIMENTS}

The first two experiments were preliminary studies and were carried out prior to Experiment 3. Experiment 1 was used to determine the actual vapor concentrations (in ppmv) of the liquid stimuli, and to ascertain the constant ratio between the two components in the mixtures. Experiment 2 was concerned with the perceptual complexity of the stimuli to be used. Experiment 3 tested the equiratio-mixture model in olfaction.

\section{Experiment 1}

\section{Method and Materials}

The stimuli used in Experiments 2 and 3 were dilutions of $\alpha$-terpineol and 1-decanol and an equiratio-mixture type (composed of these components) in diethyl phthalate. The two odorants are widely used raw materials in flavor and perfumery compositions and are both physiochemically stable. The purity of all compounds was confirmed by gas chromatography.

Of the 110 substances summarized by Patte, Etcheto, \& Laffort (1975), $\alpha$-terpineol and 1-decanol were selected because of a reasonable difference between the psychophysical power function exponents, 0.39 and 0.12 , respectively. The mixing ratio used for the construction of one particular mixture type was determined on the basis of a preliminary investigation of perceptual homogeneity. A homogeneous percept was obtained when an undiluted mixture consisted of $60 \mathrm{wt} . \% \alpha$-terpineol and $40 \mathrm{wt} . \% 1$-decanol.

The concentration series of the equiratio mixture of $\alpha$-terpineol and 1-decanol were initially calculated in the liquid phase as mole fractions $X$ (ranging from 0.07 to 0.20 ). The stimuli of each set were produced in nine equal logarithmic steps (stock solutions were stored at $4^{\circ} \mathrm{C}$ ); the $X=0.115$ equiratio-mixture concentration was used as the standard stimulus. One drop of each stimulus was deposited on a separate sniffstrip (Orlandi Inc., New York) by means of a pipette and subsequently exposed to air for $5 \frac{1}{2} \mathrm{~min}$ to let the sniffstrip absorb the liquid.

A constant vapor concentration ratio between the two odorants throughout the equiratio-mixture series could be expected, since, for such a small liquid concentration range $(X=0.04$ to 0.12 for $\alpha$-terpineol; $X=0.03$ to 0.08 for 1-decanol), Henry's law, which describes a direct proportionality between the vapor and liquid concentration, would apply (Haring, 1974). Headspace gas chromatographic analyses were carried out to verify this and to convert liquid concentration into vapor concentration units.

Headspace gas chromatography was carried out with a HewlettPackard 5890 gas chromatograph. A $2.5 \mathrm{~m} \times 530 \mu \mathrm{m}$ i.d. methyl silicone capillary column coupled to an FID $\left(260^{\circ} \mathrm{C}\right)$ was used, with $\mathrm{N}_{2}$ carrier gas $14.5 \mathrm{ml} \mathrm{min}^{-1}$, and a temperature program from $60^{\circ} \mathrm{C}$ to $210^{\circ} \mathrm{C}$ at $30^{\circ} \mathrm{C} \mathrm{min}{ }^{-1}$. The headspace sample was drawn into a sample loop with constant volume and then injected on the column. Peak areas were measured with a Hewlett-Packard 3390A integrator, and were found to be directly proportional to headspace concentrations (Kolb, 1980). The ratio between peak area at a particular odorant concentration and peak area of the saturated vapor concentration of this pure odorant gives rise to the proportion of the saturated vapor concentration, denoted as F (Appell, 1964).

\section{Results}

A constant ratio between the odorants in the headspace of the equiratio-mixture type was measured, as shown in Figure 1; the slope $F(\alpha$-terpineol $) / F(1$-decanol) was 0.938. The headspace concentration is expressed as a proportion of the saturated vapor, $F$ and multiplying $F$ by the saturated vapor concentration, $C^{\text {saturated }}$, of the compounds

(@ $20^{\circ} \mathrm{C}, C_{\text {o-terpineol }}^{\text {salurat }}=157 \mathrm{ppmv} ; C_{1-\text { decanol }}^{\text {saturated }}=2.49 \mathrm{ppmv}$;

Boublík, Fried, \& Hála, 1984) yields the vapor concentration, $C$, in parts per million by volume (ppmv).

\section{Experiment 2}

\section{Method}

Sixteen paid subjects, 8 male and 8 female students (aged 20-27), participated. None had had any previous experience in psychophysical odor experiments. No information was given about the substances used or about the purpose of the experiment.

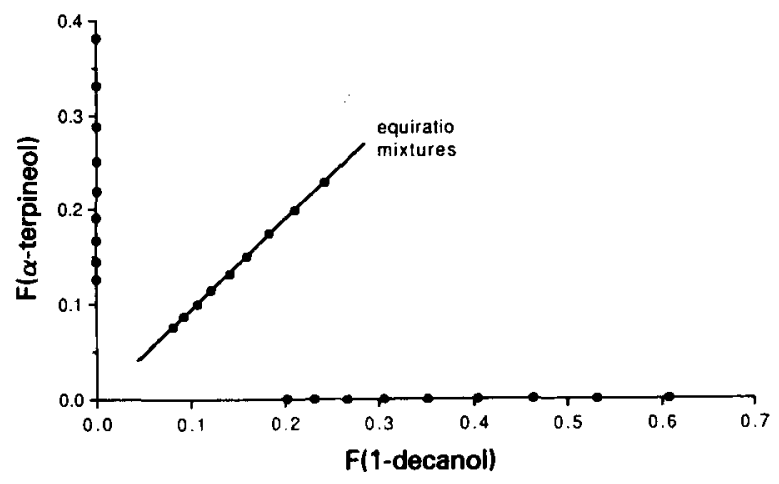

Figure 1. The 27 vapor concentrations of the two pure odorants and the equiratio-mixture type. $F$ is the proportion of the saturated vapor concentration. 


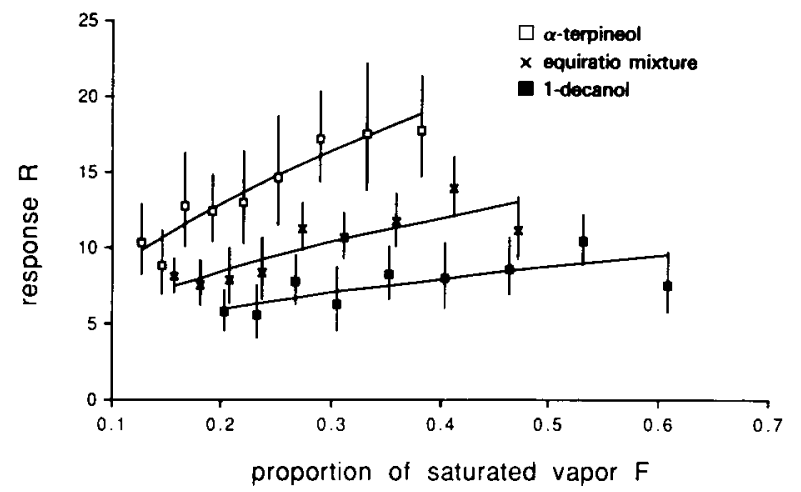

Figure 2. The two odorants and the equiratio-mixture-type responses versus proportion of saturated vapor concentration, $F$. The $95 \%$ confidence intervals are given for each presented stimulus.

One individual session was held with each of the 16 subjects to investigate the complexity of each of the stimuli that were to be used in Experiment 3. The 27 stimuli were presented in random order at 1-min intervals, and the subject was asked how many odor components $(1,2,3,4$, or more) could be distinguished within each stimulus.

\section{Results}

A Kruskal-Wallis (1952) one-way analysis of variance was used to investigate the complexity of the equiratio mixture compared with the two sets of pure odorants. The results showed that the subjects could not distinguish between the number of odor components within each stimulus set $(H=1.209 ; p<.70)$; that is, they were not able to discriminate the equiratio-mixture stimuli from the single-odorant stimuli on the basis of perceived complexity.

\section{Experiment 3}

\section{Method}

The 16 subjects in Experiment 3 were the same students who participated in Experiment 2. Again, no information was given about the substances used or about the purpose of the experiment.

Five identical sessions were held with each subject within a period of 2 weeks. In each session, each of the 27 stimuli was presented once. All stimuli were presented in randomized order, with a time interval of $1 \mathrm{~min}$ between consecutive stimuli. To prevent adaptation as much as possible, the subjects were advised not to sniff a stimulus for longer than $15 \mathrm{sec}$.
After the 9th and after the 18th stimulus, the standard stimulus was presented at the onset; its assigned odor intensity was 10 . The subjects were instructed to estimate the odor intensity of the presented stimulus as a ratio of the standard stimulus and to ignore its hedonic value. If no odor was perceived, the subject was instructed to give a zero response.

\section{Results}

The logarithm was taken of all nonzero responses per stimulus. The arithmetic mean, $\mu$, of the logarithms was converted to the geometric mean by taking the antilogarithm. The proportion of zeros is denoted as $\delta$, and the total response, $R$, per stimulus is calculated as

$$
R=(1-\delta) e^{\mu}
$$

(a reference is cited in Frijters and Oude Ophuis, 1983).

Figure 2 represents the responses, $R$, of the three concentration series against vapor concentration, $F$. The psychophysical function of the equiratio mixture lies between those of its constituents.

Psychophysical constants and exponents for the power functions of the single odorants were calculated by linear regression of log-log-transformed variables (Equations 3a and $3 \mathrm{~b}$ ); the mean of the distribution of the logtransformed responses at each stimulus level was used as the dependent variable. The psychophysical function of the equiratio mixture was calculated in the same manner (Table 1). The concentration unit is in ppmv.

The standard stimulus concentration was presented not only as the standard, but also as one of the nine mixtures. The response to this stimulus was 11.42 , slightly higher than the assigned value of 10 . Concentrations, $C_{s}$, that gave rise to the value 11.42 were

$$
C_{\alpha-\text { terpineol, }}=\left(\frac{11.42}{1.59}\right)^{1 / 0.60}=26.74 \mathrm{ppmv},
$$

and

$$
C_{1-\text { decanol,s }}=\left(\frac{11.42}{8.05}\right)^{1 / 0.43}=2.26 \text { ppmv. }
$$

The slope of vapor concentration $\alpha$-terpineol against 1-decanol in the equiratio mixtures was measured, and their ratios were $p=.983$ and $q=.017$, respectively. Using these ratios, the constants and exponents were obtained

\begin{tabular}{|c|c|c|c|c|c|c|c|}
\hline & \multicolumn{5}{|c|}{ Measured } & \multirow{2}{*}{\multicolumn{2}{|c|}{ Predicted }} \\
\hline & \multirow[b]{2}{*}{$k$} & \multirow{2}{*}{$\begin{array}{c}95 \% \\
\text { Confidence } \\
\text { Interval }\end{array}$} & & \multirow{2}{*}{$\begin{array}{c}95 \% \\
\text { Confidence } \\
\text { Interval } \\
\end{array}$} & \multirow[b]{2}{*}{$r$} & & \\
\hline & & & $n$ & & & $k$ & $n$ \\
\hline $\begin{array}{l}\alpha \text {-Terpineol } \\
\text { Equiratio-mixture } \\
1 \text {-Decanol }\end{array}$ & $\begin{array}{l}1.59 \\
2.10 \\
8.05 \\
\end{array}$ & $1.90-2.40$ & $\begin{array}{l}0.60 \\
0.51 \\
0.43 \\
\end{array}$ & $0.46-0.55$ & $\begin{array}{l}0.93 \\
0.87 \\
0.77 \\
\end{array}$ & 2.69 & 0.60 \\
\hline
\end{tabular}
from the psychophysical functions for the single odorants

Table 1

Note-The constant $k$ and exponent $n$ of the psychophysical functions are listed; $r$ is the Pearson correlation coefficient calculated on log-transformed variables. The concentration unit used in calculating $k$ and $n$ is in ppmv. 
and for the matched concentrations $C_{\alpha-t e r p i n e o l, s}$ and $C_{1-\text { decanol,s }}$; the constant and exponent for the equiratio mixture were predicted from Equation 4 (see Appendix). Statistical analysis showed that the experimentally obtained psychophysical function differed significantly from the predicted function $(p<.05)$.

The data show a relatively high degree of noise: the Pearson correlation coefficient varied between 0.77 (1-decanol) and 0.93 ( $\alpha$-terpineol). This noise may have been due in part to the small concentration range employed here, approximately a 3-to-1 span (Durlach \& Braida, 1969).

\section{DISCUSSION}

The exponent of the equiratio mixture was smaller than predicted, whereas the constant was larger. In the present study, it was difficult to decide which concentration units were best, since the concentration unit reflected directly upon the predicted constant of the equiratio-mixture (Equation 5). Various studies have specified concentration units as mass of odorant per volume of mixture with air (mg of odorant(s)/liter of air; e.g., Cain, 1975), vapor pressure (e.g., Laing et al., 1984), or parts per million (e.g., Berglund, Berglund, \& Lindvall, 1978). As outlined by Myers (1982), the most preferable unit in olfactory psychophysics is parts per million, a ratio index (i.e., molecules of odorant(s)/molecules of air), which is a unit directly proportional to the saturated-vapor pressure. Therefore, relative to compounds with high saturated vapor pressures, compounds with relatively low saturated-vapor pressures contribute little to the total vapor concentration of a mixture. This is well exemplified by the present study. The saturated-vapor pressure of $\alpha$-terpineol is 63 times higher than that of 1-decanol at room temperature. The absolute vapor concentration (in ppmv) of $\alpha$-terpineol is therefore always present at a higher concentration than 1-decanol in the equiratio-mixtures studied here. The Appendix clearly slows that $p \rightarrow q$, which reflects directly upon $n_{\text {mixture }}$; the value of $n_{\text {mixture }}$ for the present equiratiomixture type approximated $n_{\alpha-\text { terpineol }}$. If the psychophysical constants and exponents of the single constituents are calculated using $F$ as the concentration unit, then different values for the constants $k_{\mathrm{a}}$ and $k_{\mathrm{b}}$ are obtained. However, the exponents remain the same for the single constituents, because they are unit independent. In fact, the experimental exponent, 0.51 , measured for the equiratio-mixture type is similar to the one predicted. The constant $k_{\text {mixture }}$ would be overpredicted in the latter case.

A condition to be met for application of the equiratiomixture model is that the substances used are sensory dependent (i.e., show cross-adaptation). One of the causes of sensory dependency can be peripheral interaction: different molecules compete equally for the same receptor sites. Maximal competition for a receptor occurs when the experimental function is equivalent to the one predicted by the equiratio-mixture model. However, the predicted exponent over the entire equiratio-mixture concentration range is significantly higher than the one determined in the experiment, indicating that an additional suppression takes place, probably at a central level. This type of mixture suppression was earlier observed by Cain (1975): dichorinic mixtures show suppression occurring at a central level. Such suppression was less than that found in physical mixtures. The outcomes of electrophysiological studies (Derby, Ache, \& Kennel, 1985; Leveteau \& MacLeod, 1969) are also consistent with the psychophysical findings of the present study; that is, mixture suppression can exist at more than one level, peripherally or centrally, in olfaction.

\section{REFERENCES}

APPELL, L. (1964). Physical foundations in perfumery: Methodology. American Perfumer \& Cosmetics, 79, 25-39.

BERGLUND, B. (1974). Quantitative and qualitative analysis of industrial odors with human observers. Annals of the New York Academy of Sciences, 237, 35-51.

Berglund, B., Berglund, U., Lindvall, T. (1978). Separate and joint scaling of perceived odor intensity of $n$-butanol and hydrogen sulfide. Perception \& Psychophysics, 23, 313-320.

Boublí, T., Fried, V., HÁLA, E. (1984). Vapor pressures of pure substances. Amsterdam: Elsevier.

CAIN, W. S. (1969). Odor intensity: Differences in the exponent of the psychophysical function. Perception \& Psychophysics, 6, 349-354.

CAIN, W. S. (1975). Odor intensity: Mixtures and masking. Chemical Senses \& Flavor, 1, 339-352.

CAIN, W. S. (1987). Taste vs. smell in the organization of perceptual experience. In J. Solms, D. A. Booth, R. M. Pangborn, \& O. Raunhardt (Eds.), Food acceptance and nutrition (pp. 63-77). London: Academic Press.

Cain, W. S., Drexler, M. (1974). Scope and evaluation of odor counteraction and masking. Annals of the New York Academy of Sciences, 237, 427-439.

Derby, C. D., ACHE, B. W., KenNel, E. W. (1985). Mixture suppression in olfaction: Electrophysiological evaluation of the contribution of peripheral and central neural components. Chemical Senses, 10, 301-316.

Durlach, N. I., Braida, L. D. (1969). Intensity perception. 1. Preliminary theory of intensity resolution. Journal of the Acoustical Society of America, 46, 372-383.

FriJters, J. E. R. (1987). Psychophysical models for mixtures of tastants and mixtures of odorants. In S. D. Roper \& J. Atema (Eds.), Olfaction and taste IX (pp. 67-78). New York: New York Academy of Sciences.

Fruters, J. E. R., De GraAf, C. (1987). The equiratio taste mixture model successfully predicts the sensory response to the sweetness intensity of complex mixtures of sugars and sugar alcohols. Perception, 5, 615-628.

Frujters, J. E. R., De GraAF, C., Koolen, H. C. M. (1984). The validity of the equiratio taste mixture model investigated with sorbitolsucrose mixtures. Chemical Senses, 9, 241-248.

Friuters, J. E. R., Oude Ophuis, P. A. M. (1983). The construction and prediction of psychophysical power functions for the sweetness of equiratio sugar mixtures. Perception, 12, 753-767.

Friters, J. E. R., \& Stevens, D. A. (1986). Psychophysical taste functions of equiratio acid mixtures. Worcester, MA: Clark University.

Gregson, R. A. M. (1986). Qualitative and aqualitative intensity components of odor mixtures. Chemical Senses, 11, 455-470.

HARING, H. G. (1974). Vapor pressures and Raoult's law deviations in relation to odor enhancement and suppression. In A. Turk, J. W. Johnston, \& D. G. Moulton (Eds.), Human responses to environmental odors (pp. 199-226). New York: Academic Press.

JoNEs, F. N., Woskow, M. H. (1964). On the intensity of odor mixtures. Annals of the New York Academy of Sciences, 116, 484-494.

KoLB, B. (1980). Physiochemical applications for headspace gas chromatography. In B. Kolb (Ed.), Applied headspace gas chromatography (pp. 1-11). London: Heyden. 
KRUSKAL, W. H., \& WALLIS, W. A. (1952). Use of ranks in one-criterion variance analysis. Joumal of the American Statistical Association, 47, $583-621$.

LAFForT, P., Dravnieks, A. (1982). Several models of suprathreshold quantitative olfactory interaction in humans applied to binary, ternary and quaternary mixtures. Chemical Senses, 7, 153-174.

Laing, D. G., Panhuber, H., Willcox, M. E., \&ittman, E. A. (1984). Quality and intensity of binary odor mixtures. Physiology \& Behavior, 33, 309-319.

Laing, D. G., Willcox, M. E. (1983). Perception of components in binary odour mixtures. Chemical Senses, 7, 249-264.

LeVeteau, J., MACLEOD, P. (1969). Reciprocal inhibition at glomerular level during bilateral olfactory stimulation. In C. Pfaffmann (Ed.), Olfaction and Taste III (pp. 212-215). New York: Rockefeller University Press.

Moskowitz, H. R., \& BARBe, C. D. (1977). Profiling of odor components and their mixtures. Sensory Processes, 1, 212-226.

Myers, A. K. (1982). Psychophysical scaling and scales of physical stimulus measurement. Psychological Bulletin, 92, 203-214.

Patte, F., Etcheto, M., \& Laffort, P. (1975). Selected and standardized values of suprathreshold odor intensities for 110 substances. Chemical Senses \& Flavor, 1, 283-305.

\section{NOTE}

1. An earlier example in olfactory psychophysics in which a ratio between two odorants in a mixture remained constant throughout the concentration series was performed by Cain (1969, Experiment 3 ).

$$
\begin{aligned}
& \text { APPENDIX } \\
& \frac{q}{p}=\frac{q}{(1-q)}=\frac{F(1-\text { decanol }) C_{1 \text {-decanol }}^{\text {saturated }}}{F(\alpha \text {-terpineol }) C_{\alpha-\text { terpineol }}^{\text {saturated }}} \\
& =\frac{1}{0.938} \times \frac{2.49}{157}=0.017 \\
& q=0.017 \text { and } p=1-0.017=0.983 ; k_{\text {o-terpineol }}=1.59 \\
& k_{1 \text {-decanol }}=8.05 ; C_{\alpha-\text { terpineol,s }}=26.74 ; C_{1 \text {-decanol, } \mathrm{s}}=2.26 \text {. } \\
& k_{\text {mixture }}=\frac{\frac{0.983 \times 1.59}{26.74}+\frac{0.017 \times 8.05}{2.26}}{\frac{0.983}{26.74}+\frac{0.017}{2.26}}=2.69 \\
& n_{\text {mixture }}=\left(p n_{\text {o-terpineol }}\right)+\left(q n_{1-\text { decanol }}\right) \\
& =(0.983 \times 0.60)+(0.017 \times 0.43)=0.60 \text {. }
\end{aligned}
$$

Note- $p$ refers to $\alpha$-terpineol; $q$ refers to 1 -decanol.

(Manuscript received August 10, 1987; revision accepted for publication March 23, 1988.) 